\title{
Heterotopic transplantation as a model to study functional recovery of unloaded failing hearts
}

Hendrik T. Tevaearai, MD ${ }^{a, c}$

G. Brant Walton, BS ${ }^{a}$

Andrea D. Eckhart, $\mathrm{PhD}^{\mathrm{a}}$

Janelle R. Keys, $\mathrm{PhD}^{\mathrm{a}}$

Walter J. Koch, PhD a,b

From the Departments of Surgery a and Pharmacology and Cancer Biology, ${ }^{\mathrm{b}}$ Duke University Medical Center, Durham, NC, and Department of Cardiovascular Surgery, University Hospital, Lausanne, Switzerland. ${ }^{\mathrm{c}}$

Supported by grants from the Swiss National Science Foundation FN 3200065044.01 and 84NP-057501 (H.T.T.), National Institutes of Health grants HL59533 (W.J.K.) and HL 56205 (W.J.K.), and a research fellowship from Howard Hughes Medical Institute (G.B.W.).

Received for publication March 13, 2002; accepted for publication June 12, 2002.

Address for reprints: Walter J. Koch, PhD, Box 2606, MSRB Room 479, Duke University Medical Center, Durham, NC 27710 (E-mail: Koch0002@mc.duke.edu).

J Thorac Cardiovasc Surg 2002;124: 1149-56

Copyright (ङ 2002 by The American Association for Thoracic Surgery

$0022-5223 / 2002 \$ 35.00+0 \quad \mathbf{1 2 / 1 / 1 2 7 3 1 5}$

doi:10.1067/mtc.2002.127315
Objectives: Recent studies have demonstrated cardiac improvement in patients supported with a ventricular assist device, suggesting that reverse remodeling and myocardial recovery are possible. We developed an animal model of cardiac unloading by adapting a heterotopic transplantation technique and used it to examine the pattern of functional recovery in the left ventricle of the failing heart.

Methods: Heart failure was induced in adult New Zealand rabbits by coronary artery ligation with subsequent myocardial infarction. Animals undergoing sham operation served as a control group. After 4 weeks or 3 months, failing hearts were transplanted into the necks of recipient rabbits. A left ventricular latex balloon connected to subcutaneous tubing allowed repeated physiologic analysis on days 1 and after transplantation and then every 5 days until day 30 .

Results: Contractility (left ventricular $\mathrm{dP} / \mathrm{dt}_{\max }$ ) and relaxation (left ventricular $\mathrm{dP} / \mathrm{dt}_{\text {min }}$ ) were significantly lower in transplanted postinfarction hearts as compared to control hearts immediately after transplantation. Both left ventricular $\mathrm{dP} / \mathrm{dt}_{\max }$ and left ventricular $\mathrm{dP} / \mathrm{dt}_{\min }$ responses to increased preload and to $\beta$-adrenergic stimulation progressively improved to a significantly higher level after 30 days of left ventricular unloading for the hearts that were transplanted 4 weeks after myocardial infarction. However, this functional improvement was not detected in failing hearts transplanted 3 months after infarction.

Conclusions: This model of cardiac unloading appears at least partially to mimic conditions of ventricular assist devices. If performed early in the development of heart failure, it permits improvement of contractile dysfunction and restoration of cardiac responsiveness to mechanical and $\beta$-adrenergic stimulation. Therefore this model may constitute a novel alternative in the study of reverse remodeling in unloaded failing hearts.

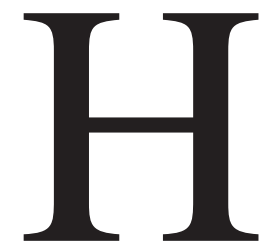

emodynamic support with a ventricular assist device (VAD) is usually reserved for selected patients waiting for an organ donor, making VAD use mostly a bridge to transplantation. Interestingly, a few studies have recently reported significant left ventricular (LV) functional improvement in some patients supported with mechanical pumps. ${ }^{1-3}$ Therefore VADs may be used as a bridge to recovery, easing the need for cardiac transplantation. To date, a handful of human studies have analyzed LV samples obtained from hearts supported with a VAD at the time of cardiac transplantation. These analyses have shown partial reversal of the histologic and biochemical alterations observed in failing hearts. ${ }^{4-8}$ Clearly, understanding this apparent reverse remodeling process that takes place during ventricular unloading could help to develop new strategies or molecular approaches that could favor functional recovery in assisted hearts. 


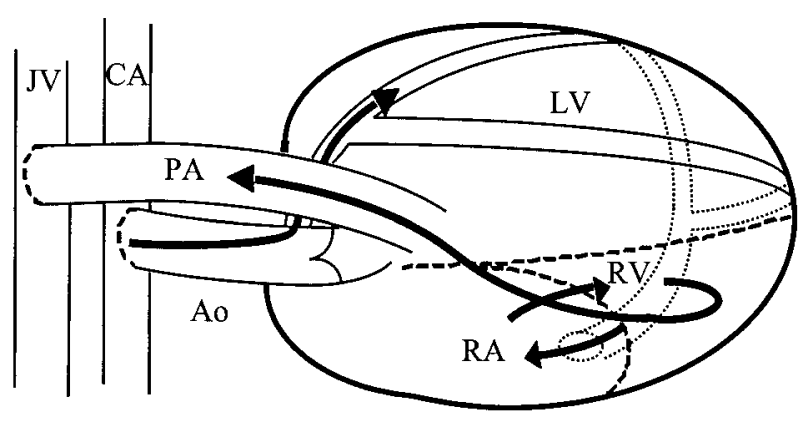

Figure 1. Schematic representation of blood circulation within heterotopically transplanted heart. 0xygenated blood originating from one recipient artery (carotid artery [CA] in our case) retroperfuses donor aorta $(\mathrm{Ao})$ and irrigates coronary arteries of transplanted heart while aortic valve prevents regurgitation into LV. Coronary sinus drains myocardial blood into right cavities, whence it is ejected toward donor pulmonary artery (PA) and recipient vein (jugular vein [JV] in our case). $R A$, Right atrium; $R V$, right ventricle.

The method of heterotopic transplantation involves having the heart perfused by circulating blood that is shunted from the LV cavity. Thus heterotopically transplanted hearts are, in essence, unloaded (Figure 1). The purpose of this study was to evaluate heterotopic heart transplantation in the rabbit as a model of LV unloading for failing hearts. In this study we transplanted failing hearts 4 weeks or 3 months after myocardial infarction (MI) and evaluated physiologic and biochemical indices of reverse remodeling. Our data confirmed the role of mechanical unloading for potential recovery of LV contractility and relaxation, especially with regard to restoration of functional recovery to $\beta$-adrenergic receptor agonist stimulation. Moreover, we demonstrated the deleterious effect on the potential for functional recovery of any delay in the assistance of the failing ventricle.

\section{Methods}

\section{Coronary Artery Ligation}

Adult male New Zealand White rabbits $(3 \mathrm{~kg}$ ) were used. All procedures were humanely performed in accordance with the Guide for the Care and Use of Laboratory Animals prepared by the Institute of Laboratory Animal Resources, National Research Council, and published by the National Academy Press, revised 1996, and were approved by the Animal Care and Use Committee of Duke University. Animals were anesthetized with ketamine (60 $\mathrm{mg} / \mathrm{kg}$ ) and acepromazine maleate (INN: acepromazine, $1.0 \mathrm{mg} /$ $\mathrm{kg}$ ), intubated, and mechanically ventilated. MI was induced by ligation of a marginal branch of the left circumflex coronary artery as previously described elsewhere. ${ }^{9,10}$ Sham operations on control animals consisted of thoracotomy and opening of the pericardium only.

\section{Heterotopic Transplantation}

Both donor and recipient animals (3-kg male New Zealand White rabbits) were anesthetized as described. Cardioplegic arrested donor hearts were transplanted into the cervical location of the recipient rabbit with anastomoses of the donor ascending aorta to the recipient carotid artery and the donor pulmonary artery to the recipient jugular vein. ${ }^{11}$ Dexamethasone $(4 \mathrm{mg} / \mathrm{kg})$ was administered intravenously before reperfusion as well as on every subsequent postoperative day. Special care was taken to remove the air from the cardiac cavities before unclamping. Hearts resumed vigorous contraction within 3 minutes of reperfusion. Total cold ischemic time approximated 45 minutes. In summary, donor carotid arterial blood retroperfused the ascending aorta of the transplanted heart and normally irrigated its coronaries. Blood was then drained into the right atrium before being directed to the right ventricle and ejected into the pulmonary artery and the recipient jugular vein (Figure 1). Thus the left heart cavities were entirely shunted, and consequently the LV was unloaded.

\section{Left Ventricular Balloon Positioning and Repeated Left Ventricular Functional Assessment}

A latex balloon was positioned in the LV cavity through the left atrium and mitral valve. The balloon was connected to a piece of tubing conducted under the skin toward the animal's back. This system permitted a remote access to the LV cavity so that recording of LV pressures could be performed repeatedly with the animal under light anesthesia (ketamine at $40 \mathrm{mg} / \mathrm{kg}$ and acepromazine at $0.5 \mathrm{mg} / \mathrm{kg}$ ) initially on days 1 and 5 and subsequently every 5 days through day 30. Except during measurement procedures, the balloon was kept deflated to allow complete LV unloading. For measurements a high-fidelity pressure transducer (Millar Instruments, Inc, Houston, Tex) was introduced into the tubing until its tip was into the LV balloon. Basal LV end-diastolic volume (LVEDV) was standardized by adjusting the balloon volume to give the LV end-diastolic pressure (LVEDP) of $0 \mathrm{~mm} \mathrm{Hg}$. Three preload conditions were studied (baseline, $0.1 \mathrm{~mL}$, and $0.3 \mathrm{~mL}$ ). In addition, we tested the response to stimulation with the $\beta$-adrenergic agonist isoproterenol (INN isoprenaline).

\section{Statistical Analysis}

Data are expressed as mean \pm SEM. Unpaired Student $t$ tests were used for comparisons between groups. One-way analysis of variance for repeated measures with the Tukey-Kramer posttest correction was used to analyze ventricular function after heterotopic transplantation.

\section{Results}

We considered LV function measured 24 hours after heterotopic transplantation as baseline function so that the potential effects of cardioplegia after the surgical procedure could be considered nonsignificant. Our extensive experience with this rabbit MI model has demonstrated that LV infarct size must be at least $30 \%$ of the free wall to induce significant heart failure in rabbits at 3 to 4 weeks after MI. ${ }^{9}$ Therefore hearts with a smaller infarction were not used for heterotopic transplantation. Accordingly, hearts after MI had a significantly diminished $\mathrm{LV}$ function relative to a 

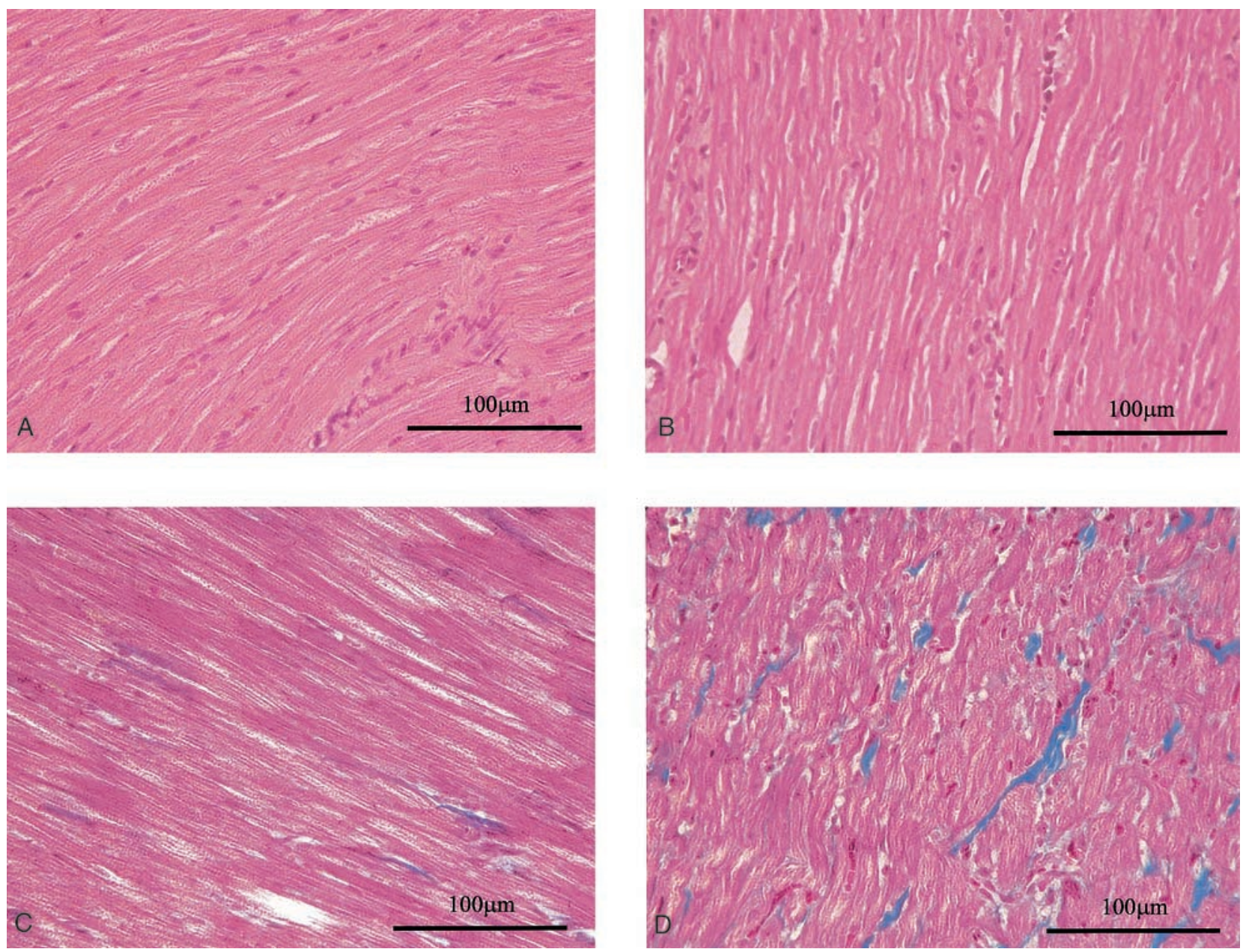

Figure 2. Comparison of representative histologic slices obtained from native heart of recipient rabbit $(A$ and $C)$ and from heterotopically transplanted heart $\mathbf{3 0}$ days after transplantation (B and D). Slight infiltration with polymorphonuclear cells ( $B$, hematoxylin and eosin) and zones of fibrosis (D, trichrome-Masson stain) can be seen in heterotopically transplanted heart as compared with native heart ( $A$, hematoxylin and eosin; $C$, trichrome-Masson stain), accounting for moderate chronic rejection.

control group of heterotopically transplanted hearts with sham ligation. Several parameters were altered in the failing

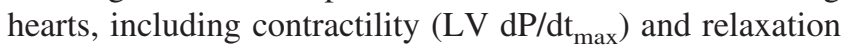
$\left(\mathrm{LV} \mathrm{dP/dt} t_{\min }\right.$ ) under basal conditions as well as in response to increased preload or to the $\beta$-adrenergic receptor agonist isoproterenol (data not shown). Importantly, the degree of heart failure 4 weeks after LV infarction was stable, with no significant functional changes observed in hearts analyzed 3 months after infarction.

Whereas a single initial dose of steroids allowed the heart to beat for only 7 days (data not shown), a daily dose of dexamethasone permitted the heterotopically transplanted heart to beat normally and regularly for more than 30 days. Moreover, histologic examination of tissues from animals that received a single dose of steroids at the time of heterotopic transplantation demonstrated a massive immune reaction 5 days after heterotopic transplantation (data not shown), whereas only a moderate infiltration was present after 30 days in hearts treated with a daily dose of steroids (Figure 2). The reason for this reaction is that, unlike the isogenic strains of rats in which this heterotopic transplantation technique is widely used, farm-raised rabbits are allogeneic, and thus this procedure cannot be considered an isograft condition.

LV function was assessed every 5 days until day 30 after heterotopic transplantation. In assessing recovery of the ventricular functional response to preload, both LV contractility ( $\mathrm{LV} \mathrm{dP} / \mathrm{dt}_{\max }$ ) and $\mathrm{LV}$ relaxation $\left(\mathrm{LV} \mathrm{dP} / \mathrm{dt}_{\min }\right)$ responses to the higher LVEDV $(0.3 \mathrm{~mL})$ tested were significantly improved relative to an LVEDV of $0.1 \mathrm{~mL}$ (Figure 3 ). Similarly, we observed a recovery of the response to stimulation with the $\beta$-adrenergic receptor agonist isopro- 

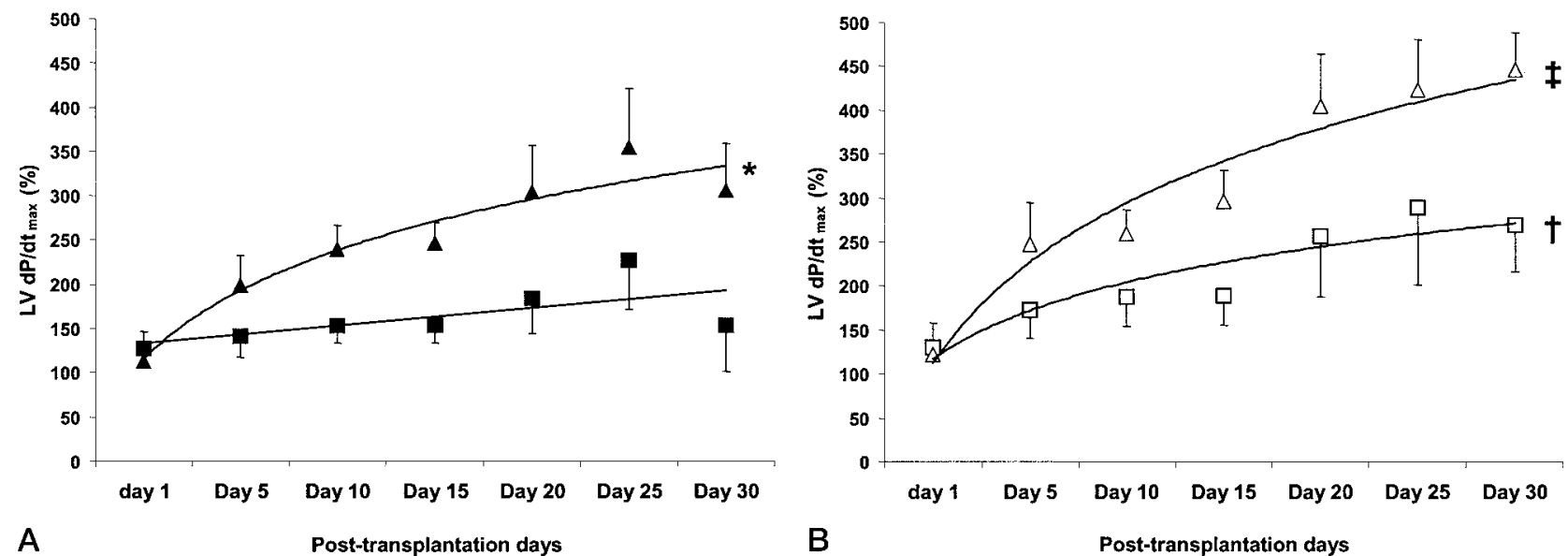

A

Post-transplantation days

B
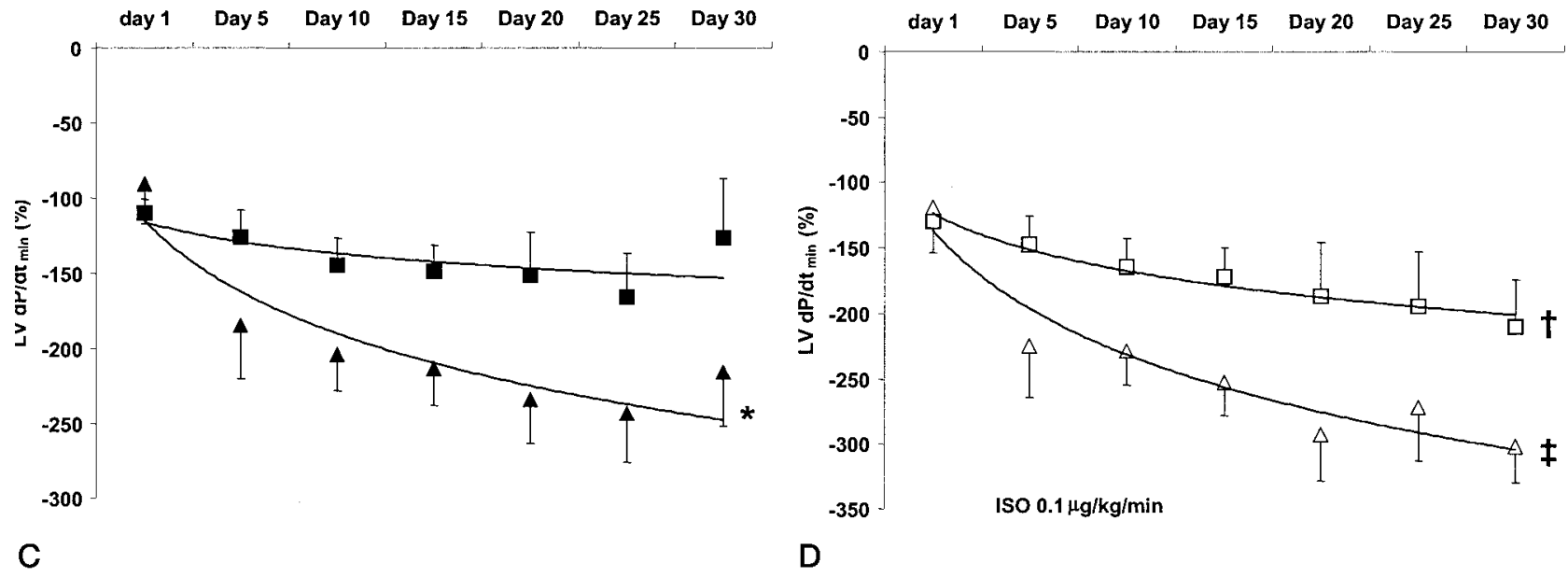

Figure 3. LV contractility (LV dP/dt max $A$ and $B$ ) and relaxation ( $L V d P / d t_{\min ^{\prime}}, C$ and $\left.D\right)$ in failing hearts unloaded for 30 days $(n=5)$. Values were obtained every 5 days, with ( $B$ and $D)$ or without $(A$ and $C)$ stimulation with isoproterenol (ISO) at $0.1 \mu \mathrm{g} /(\mathrm{kg} \cdot \mathrm{min}$ ) under two preload conditions: LVEDV of basal plus $0.1 \mathrm{~mL}$ (open squares and filled squares) and LVEDV of basal plus $0.3 \mathrm{~mL}$ (open triangles and filled triangles). Results are expressed as percentage of basal value obtained at day 1 with preload of $0 \mathrm{~mL}$ and without isoproterenol stimulation. Asterisk indicates $\boldsymbol{P}<.05$ by 1 -way analysis of variance for repeated measures; dagger indicates $\boldsymbol{P}<.05$ for preload of basal plus $0.1 \mathrm{~mL}$; double dagger indicates $P<.001$ for preload of basal plus $0.3 \mathrm{~mL}$.

terenol (Figure 3). Also, the pressure/volume relationship significantly increased during this period (Figure 4). Thus unloading of the failing heart by heterotopic transplantation resulted in sustained reversal of ventricular dysfunction.

Myocardial functional recovery of failing hearts is difficult to predict, because it certainly depends on reversibility of cellular alterations that take place progressively during the development of heart failure. We therefore hypothesized that prolonged delay before ventricular unloading might impair the potential for functional recovery. To verify this assumption, we compared functional evolution during a 20-day period of ventricular unloading in hearts that were in failure for 3 weeks versus 3 months. Interestingly, we found that after a postinfarction delay of 3 months before heterotopic transplantation and subsequent ventricular unloading, no significant improvement in LV function could be observed in any of the conditions tested (Figure 5). In addition, the LV pressure generated during systole did not improve after 20 days of ventricular unloading in hearts in failure for 3 months, whereas a significant increase was observed in hearts supported by heterotopic transplantation 3 weeks after MI (Figure 6).

\section{Discussion}

Other than studies of human samples obtained from VADsupported failing hearts at the time of transplantation, only a few animal studies have examined the effects of myocardial unloading, ${ }^{12,13}$ and to date no animal model of cardiac unloading of failing hearts has been well characterized. The heterotopically transplanted heart reproduces, at least in 


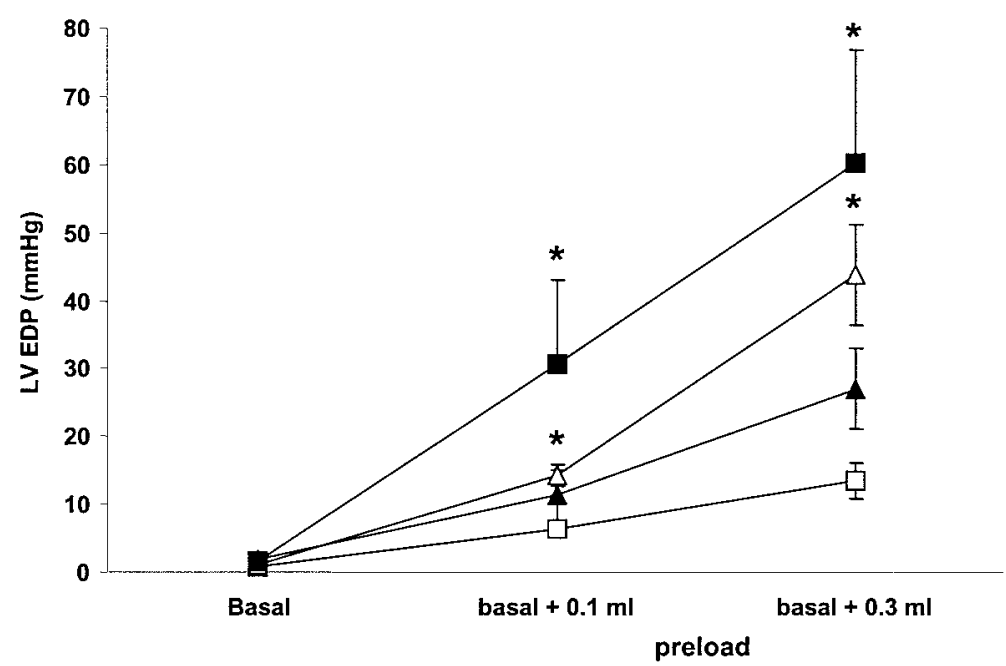

Figure 4. Progression of LV pressure/volume relationship in unloaded failing hearts (4 weeks after coronary ligation, $\mathbf{n}=5$ ). LVEDP responses to increased preload are shown for day 1 (open squares), day 5 (filled triangles), day 15 (open triangles), and day 30 (filled squares). Asterisk indicates $P<.05$ versus day 1.

part, the situation of a mechanically assisted LV. Although it is normally perfused, the LV is entirely unloaded, providing the aortic valve is competent. We used an adapted technique to assess LV function repeatedly in lightly anesthetized rabbits. ${ }^{14}$ With this model, we showed that LV function of failing rabbit hearts can partially recover when unloaded for a sufficient period. Interestingly, we observed no significant improvements in contractility and relaxation in ventricles preloaded with small LVEDV as we adjusted LVEDV to $0 \mathrm{~mm} \mathrm{Hg}$ as our basal condition. However, during the initial 30 days of ventricular unloading, we observed a progressive improvement in the functional response to increased preload as well as to $\beta$-adrenergic receptor agonist stimulation. Therefore both mechanical and hormonal responses were restored in these hearts. These findings are important, because they confirm this model to be a reproducible way of studying ventricular recovery after development of heart failure. Importantly, these findings also mimic observations recently completed in human studies in which the use of a mechanical VAD allowed improvement of ventricular function and, in some cases, weaning from the mechanical pump. ${ }^{15}$

Functional improvement was first reported in case reports ${ }^{16-20}$ before a few series of patients supported these observations. ${ }^{1-3,21,22}$ In addition, recovery of contractile function was confirmed in vitro with isolated human cardiomyocytes. ${ }^{6,23}$ Because donor organs remain a major limiting factor for cardiac transplantation, the concept of reverse remodeling and myocardial recovery is extremely attractive. However, factors affecting recovery are poorly understood, even though molecular changes have clearly been demonstrated in unloaded human ventricles. For example, tran- scription of apoptosis-inhibiting genes is upwardly regulated, ${ }^{7,24}$ endothelin receptor A level is normalized, ${ }^{8}$ interleukin 6 and 8 levels are normalized, ${ }^{25}$ sarcoplasmic endoreticular calcium adenosine triphosphatase subtype $2 \mathrm{a}$ protein level is increased, and gene expressions of other proteins involved in the myocardial calcium metabolism are increased. ${ }^{23}$ Desensitization of the $\beta$-adrenergic receptor system is one of the characteristic alterations observed in cardiomyocytes from failing hearts. ${ }^{9,26}$ Consequently, response to $\beta$-adrenergic receptor stimulation is limited in patients as well as in animal models of heart failure, including rabbits with coronary ligation.9,10 Thus restoration of the $\beta$-adrenergic receptor level might be one of the mechanisms involved in functional recovery in unloaded failing hearts. This speculation is supported by our observation of a progressive improvement in contractile function in response to $\beta$-adrenergic receptor stimulation and is also supported by other studies performed with human samples. ${ }^{6}$

Myocardial recovery after VAD support is generally unpredictable. However, it is generally agreed that prolonged heart failure leads to sustained myocardial remodeling and eventually to irreversible damage. ${ }^{27}$ Subsequently, the chance for myocardial recovery is impaired. For various reasons, management of HF usually involves VAD implantation as a last chance solution, mostly as a bridge to transplantation. By this time of end-stage heart failure, most hearts have extended myocardial cellular and extracellular alterations together with multiple organ dysfunction. This probably at least in part explains the low incidence of myocardial recovery observed in large series of VAD placements. ${ }^{2}$ Our data are in accordance with these clinical observations, with no recovery of failing rabbit hearts that 

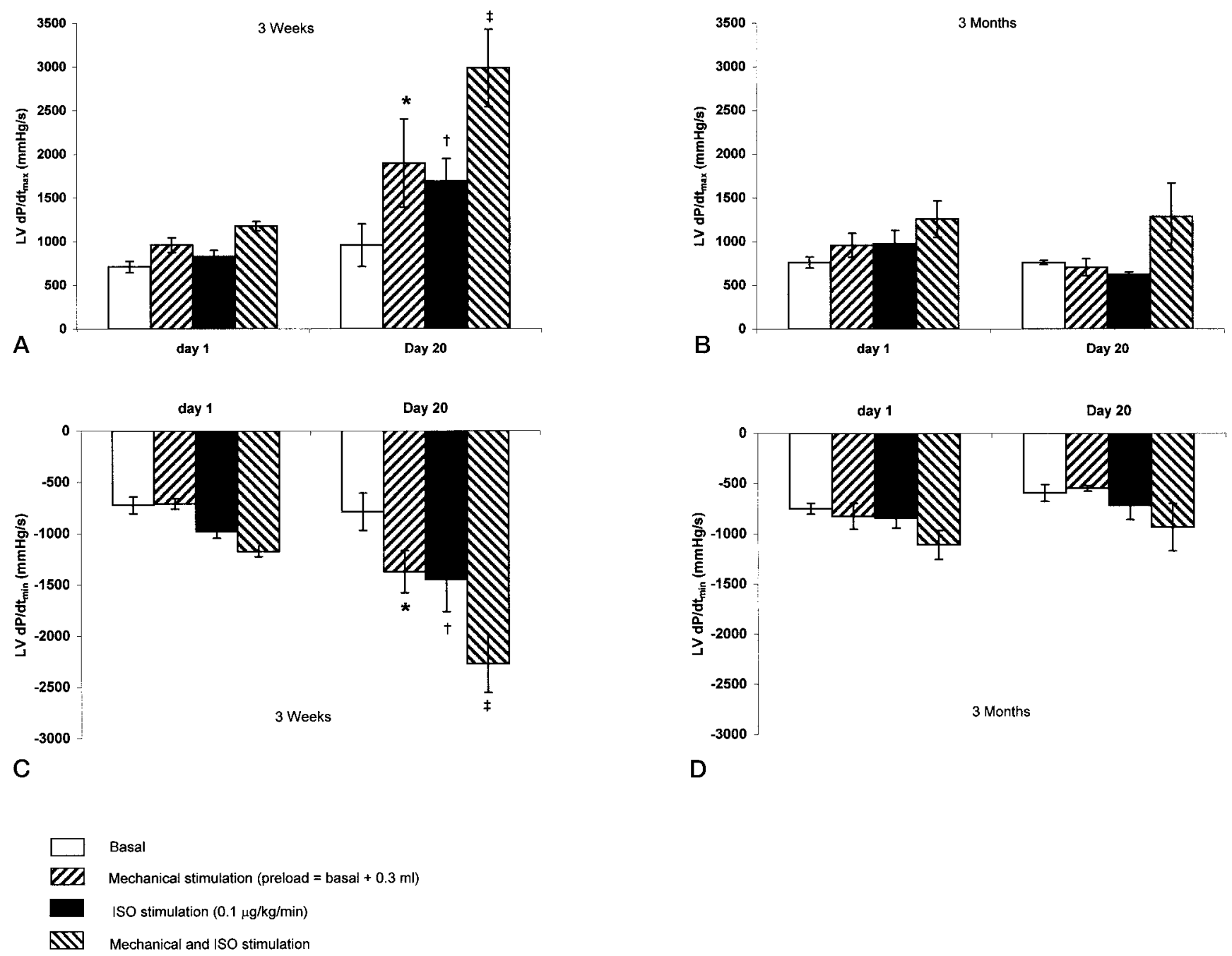

Figure 5. Comparison of 20-day period of unloading on ventricular function in failing hearts 3 weeks after coronary ligation ( $n=5, A$ and C) versus 3 months after coronary ligation ( $=3, B$ and D). LV contractility (LV dP/dt max' $^{\prime}$ $A$ and $B$ ) and relaxation (LV dP/dt ${ }_{\text {min }}, C$ and $D$ ) are shown for different hemodynamic conditions. Asterisk indicates $\boldsymbol{P}<.05$ for basal versus mechanical stimulation; dagger indicates $\boldsymbol{P}<.05$ for basal versus isoproterenol (ISO) stimulation; double dagger indicates $\boldsymbol{P}<.001$ for basal versus mechanical and isoproterenol stimulation.

were held 3 months after MI before being unloaded by heterotopic transplantation. In these hearts, as opposed to failing hearts assisted earlier in the development and progression of heart failure, basal LV function as well as response to mechanical and $\beta$-adrenergic receptor stimulation did not improve during an unloading period of 20 days. This model thus confirms the clinical suspicion that the delay before ventricular unloading represents a critical factor for successful functional recovery. ${ }^{15}$

Samples obtained from patients' LVs at the time of VAD implantation or heart transplantation have predominantly been used to analyze histologic, biochemical, and molecular changes that occur in unloaded hearts. Even though analyzing reverse remodeling in humans is an ultimate goal, this approach presents several limitations. First of all, the limited use of VADs and an insufficient pool of organ donors make the number of samples available for laboratory analysis extremely low. Moreover, as stated previously, VADs are usually used late in the course of heart failure and thus represent an advanced, mostly irreversible, stage of heart failure. Cardiomyopathy may also be due to various etiopathologic mechanisms, and different types of medical treatment may support the patients. Such heterogeneity makes the results difficult to interpret, especially when looking for prognostic factors for recovery. With these complexities in mind, our rabbit model of heterotopic transplantation constitutes an attractive and relatively rapid and feasible way to better characterize the reverse remodeling 


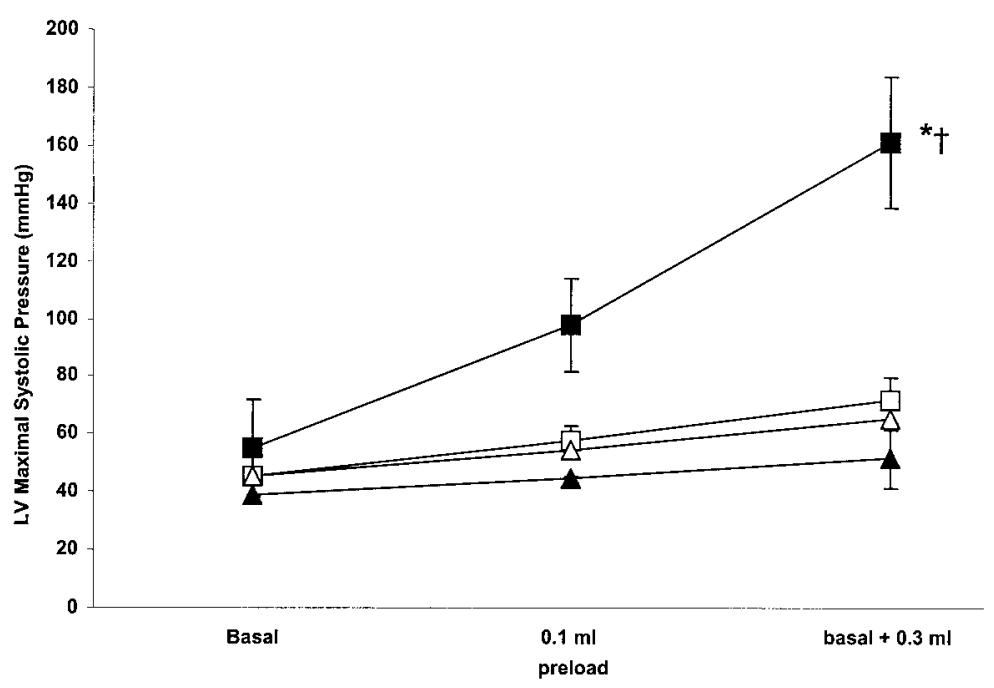

Figure 6. Comparison of LV systolic pressures in response to mechanical stimulation measured on day 1 (open squares and open triangles) and day 20 (filled squares and filled triangles) after heterotopic heterotopic transplantation and ventricular unloading of failing hearts. Hearts were transplanted 3 weeks (open squares and filled squares, $\mathbf{n}=5$ ) or 3 months (open triangles and filled triangles) after coronary ligation. Asterisk indicates $P=.01$ for added preload of $0.3 \mathrm{~mL}$ versus basal; dagger indicates $\boldsymbol{P}<.005$ for day 20 versus day 1 .

processes that occur during ventricular unloading. Importantly, it may allow correlation of biochemical or molecular findings with the presence or absence of functional recovery.

In conclusion, the heterotopic transplantation technique in small animals reproduces the situation of an unloaded heart and potentially offers significant insight into the mechanisms of myocardial recovery. Reverse alteration of $\beta$-adrenergic receptor signaling may be critically involved in this process. Although further investigations are required, our findings suggest that VAD support, possibly in combination with other therapeutic modalities such as gene therapy, ${ }^{11,28}$ might be beneficial in terms of functional recovery in a greater proportion of cases.

We thank K. Campbell for excellent technical assistance.

\section{References}

1. Mancini DM, Beniaminovitz A, Levin H, Catanese K, Flannery M, DiTullio M, et al. Low incidence of myocardial recovery after left ventricular assist device implantation in patients with chronic heart failure. Circulation. 1998;98:2383-9.

2. Pietsch L, Laube H, Baumann G, Konertz W. Recovery from endstage ischemic cardiomyopathy during long-term LVAD support. Ann Thorac Surg.1998;66:555-7.

3. Hetzer R, Muller J, Weng Y, Wallukat G, Spiegelsberger S, Loebe M. Cardiac recovery in dilated cardiomyopathy by unloading with a left ventricular assist device. Ann Thorac Surg. 1999;68:742-9.

4. McCarthy PM, Nakatani S, Vargo R, Kottke-Marchant K, Harasaki H, James KB, et al. Structural and left ventricular histologic changes after implantable LVAD insertion. Ann Thorac Surg. 1995;59:609-13.

5. Zafeiridis A, Jeevanandam V, Houser SR, Margulies KB. Regression of cellular hypertrophy after left ventricular assist device support. Circulation. 1998;98:656-62.
6. Dipla K, Mattiello JA, Jeevanandam V, Houser SR, Margulies KB. Myocyte recovery after mechanical circulatory support in humans with end-stage heart failure. Circulation. 1998;97:2316-22.

7. Bartling B, Milting H, Schumann H, Darmer D, Arusoglu L, Koerner $\mathrm{MM}$, et al. Myocardial gene expression of regulators of myocyte apoptosis and myocyte calcium homeostasis during hemodynamic unloading by ventricular assist devices in patients with end-stage heart failure. Circulation. 1999;100 (Suppl):II-216-23.

8. Morawietz H, Szibor M, Goettsch W, Bartling B, Barton M, Shaw S, et al. Deloading of the left ventricle by ventricular assist device normalizes increased expression of endothelin $\mathrm{ET}_{\mathrm{A}}$ receptors but not endothelin-converting enzyme-1 in patients with end-stage heart failure. Circulation. 2000;102 Suppl 3):III188-93.

9. Maurice JP, Shah AS, Kypson AP, Hata JA, White DC, Glower DD, et al. Molecular $\beta$-adrenergic signaling abnormalities in failing rabbit hearts after infarction. Am J Physiol. 1999;276(6 pt 2):H1853-60.

10. White DC, Hata JA, Shah AS, Glower DD, Lefkowitz RJ, Koch WJ. Preservation of myocardial $\beta$-adrenergic receptor signaling delays the development of heart failure after myocardial infarction. Proc Natl Acad Sci U S A. 2000;97:5428-33.

11. Shah AS, White DC, Tai O, Hata JA, Wilson KH, Pippen A, et al. Adenovirus-mediated genetic manipulation of the myocardial $\beta$-adrenergic signaling in transplanted hearts. $J$ Thorac Cardiovasc Surg. 2000;120:581-8.

12. Depre C, Shipley GL, Chen W, Han Q, Doenst T, Moore ML, et al. Unloaded heart in vivo replicates fetal gene expression of cardiac hypertrophy. Nat Med. 1998;4:1269-75.

13. Lisy O, Redfield MM, Jovanovic S, Jougasaki M, Jovanovic A, Leskinen $\mathrm{H}$, et al. Mechanical unloading versus neurohumoral stimulation on myocardial structure and endocrine function in vivo. Circulation. 2000;102:338-43.

14. Dambrin C, El Feghaly M, Abbal M, Glock Y, Durand D, Fournial G, et al. A new rejection criteria in the heterotopically placed rat heart by non-invasive measurement of $\mathrm{Dp} / \mathrm{Dt}_{\max } . J$ Heart Lung Transplant. 1999;18:524-31.

15. Hetzer R, Muller JH, Weng YG, Loebe M, Wallukat G. Midterm follow-up of patients who underwent removal of a left ventricular assist device after cardiac recovery from end-stage cardiomyopathy. J Thorac Cardiovasc Surg. 2000;120:843-53. 
16. Rockman HA, Adamson RM, Dembitsky WP, Bonar JW, Jaski BE. Acute fulminant myocarditis: long-term follow-up after circulatory support with left ventricular assist device. Am Heart J. 1991;121: 922-6.

17. Hohlman WL, Bourge RC, Kirklin JK. Case report: circulatory support for 70 days with resolution of acute heart failure. J Thorac Cardiovasc Surg. 1991;102:932-33.

18. Reiss N, el Banayosy A, Posival H, Morshuis M, Minami K, Korfer R. Management of acute fulminant myocarditis using circulatory support systems. Artif Organs. 1996;20:964-70.

19. Levin HR, Oz MC, Catanese KA, Rose EA, Burkhoff D. Transient normalization of systolic and diastolic function after support with a left ventricular assist device in a patient with dilated cardiomyopathy. J Heart Lung Transplant. 1996;15:840-2.

20. Martin J, Sarai K, Schindler M, van de Loo A, Yoshitake M, Beyersdorf F. MEDOS HIA-VAD biventricular assist device for bridge to recovery in fulminant myocarditis. Ann Thorac Surg. 1997;3:1145-6.

21. Frazier OH, Benedict CR, Radovancevic B, Bick RJ, Capek P, Springer WE, et al. Improved left ventricular function after chronic left ventricular unloading. Ann Thorac Surg. 1996;62:675-82.

22. Hetzer R, Muller JH, Weng Y, Meyer R, Dandel M. Bridging-torecovery. Ann Thorac Surg 2001;71 Suppl:S109-13.

23. Heerdt PM, Holmes JW, Cai B, Barbone A, Madigan JD, Reiken S, et al. Chronic unloading by left ventricular assist device reverses contractile dysfunction and alters gene expression in end-stage heart failure. Circulation. 2000;102:2713-9.

24. Milting H, Bartling B, Schumann H, El Banayosy A, Wlost S, Ruter $\mathrm{F}$, et al. Altered levels of mRNA of apoptosis-mediating genes after mid-term mechanical ventricular support in dilative cardiomyopathy: first results of the Halle Assist Induced Recovery Study (HAIR). Thorac Cardiovasc Surg. 1999;47:48-50.

25. Goldstein DJ, Moazami N, Seldomridge JA, Laio H, Ashton RC, Naka $\mathrm{Y}$, et al. Circulatory resuscitation with left ventricular assist device support reduces interleukins 6 and 8 levels. Ann Thorac Surg. 1997; 63:971-4.

26. Akhter SA, Skaer CA, Kypson AP, McDonald PH, Peppel KC, Glower DD, et al. Restoration of $\beta$-adrenergic signaling in failing cardiac ventricular myocytes via adenoviral-mediated gene transfer. Proc Natl Acad Sci U S A. 1997;94:12100-5.

27. Mann DL, Willerson JT. Left ventricular assist devices and the failing heart: a bridge to recovery, a permanent device, or a bridge too far? Circulation. 1998;98:2367-9.

28. Kypson A, Hendrickson S, Akhter S, Wilson K, McDonald P, Lilly R, et al. Adenovirus-mediated gene transfer of the $\beta_{2}$-adrenergic receptor to donor hearts enhances cardiac function. Gene Ther. 1999;6:1298304 